\title{
Assessing Cognitive Function and Capacity in Older Adults With Cancer
}

June M. McKoy, MD, MPH, JD, MBA a,b; Peggy S. Burhenn, MSc: Ilene S. Browner, MD; Kari L. Loeser, JD ; Katrina M. Tulas, BS ${ }^{\mathrm{b}}$; Megan R. Oden, BA ${ }^{\mathrm{a}, \mathrm{b}}$; and Randall W. Rupper, MD, MPH ${ }^{\mathrm{f}, \mathrm{g}}$

\begin{abstract}
The number of older individuals with cancer is increasing exponentially, mandating that oncologists contemplate more comprehensive and multidisciplinary approaches to treatment of this cohort. Recruitment of assessment instruments validated in older patients can be invaluable for guiding treatment and decision-making by both patients and providers, and can arguably contribute to improving outcomes and health-related quality of life. The Comprehensive Geriatric Assessment is one such validated instrument that can be used by oncologists to assess patient readiness and appropriateness for prescribed cancer therapy. As a multidisciplinary diagnostic and treatment process, it comprises functional status, cognitive status, social support, and advance care preferences, and is an ideal instrument for evaluating complex older individuals. It is well established that many older individuals with cancer travel with multiple comorbid illnesses, including cognitive impairment, and when presented with a cancer diagnosis struggle to choose from multiple treatment options. In addition to the complete medical history, the ability of patients to decide on a course of therapy in concert with their oncologist is critically important. Alternatively, many oncologists are conflicted as to whether true informed consent for treatment can be obtained from many older patients. Having a roadmap to decision-making capacity is therefore an inescapable imperative in geriatric oncology, because careful attention must be directed at identifying older patients with cancer who might benefit from these assessments and the individualized treatment plans that emerge. (J Natl Compr Canc Netw 2014;12:138-144)
\end{abstract}

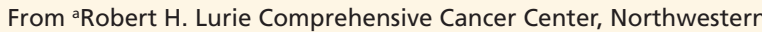
University, Chicago, Illinois; ' ${ }^{b}$ Northwestern University Feinberg

School of Medicine, Chicago, Illinois; 'City of Hope National

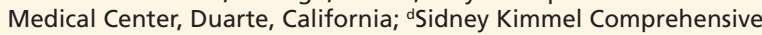

Cancer Center, Baltimore, Maryland; 'Corporate Compliance

Department, Jazz Pharmaceuticals, Palo Alto, California; fUniversity

of Utah School of Medicine, Salt Lake City, Utah; and 'Salt Lake

City VA Geriatric Research Education and Clinical Center, Salt Lake

City, Utah.

Submitted August 11, 2013; accepted for publication

November 20, 2013

The authors have disclosed that they have no financial interests, arrangements, affiliations, or commercial interests with the

manufacturers of any products discussed in this article or their

competitors. This work was supported by the National Cancer

Institute at the National Institutes of Health (1K01CA134554-05 to

JMM).

Correspondence: June M. McKoy, MD, MPH, JD, MBA

Northwestern University Feinberg School of Medicine, 750 North

Lakeshore Drive, 10th Floor, Chicago, IL 60611.

E-mail: j-mckoy@northwestern.edu

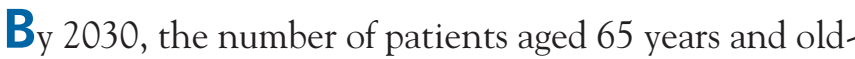
er is expected to double. With aging comes an increased cancer incidence, and more than $60 \%$ of all cancers occur in individuals aged 65 years and older. Attendant to this aging explosion are physiologic changes that sometimes result in decreased cognition and physical functioning. ${ }^{1}$ It is also well established that the underlying health status, and not the chronologic age, determines a patient's ability to tolerate medical or surgical treatment. Many older patients may retain both sufficient physical and cognitive reserve to successfully complete chemotherapy, radiation therapy, and surgical treatment, despite their chronologic age. For example, the life expectancy of a healthy 80 -year-old woman is approximately 10 years, $^{2}$ and therefore serious consideration should be given to providing cancer therapy to these patients. Tools that can assist oncologists in predicting mortality and morbidity among older prospective treatment candidates should therefore be incorporated into the clinical plan of care.

The Comprehensive Geriatric Assessment (CGA) is one such tool that can be recruited within the geriatric oncology domain to assess functional status (cognitive and physical), nutritional status, impact of comorbid conditions, and degree of social support..$^{3-5}$ The CGA summarily augments the ability of medical providers to choose appropriate treatment modalities tailored to each older patient diagnosed with cancer. Undoubtedly, older individuals with cancer must be able to navigate complex cancer treatment and communicate with their treatment providers about toxicities of treatment if and when they occur. This article outlines the evidence, including that from the literature, that provides guidance on how to assess cognitive function and decisional capacity in older individuals with cancer. 


\section{Using the CGA in Cognitive Determination}

Cognitive assessment is a key component of a CGA. A cognitive assessment is needed to understand the accuracy of the patient-provided history, to determine whether a patient has the decisional capacity to consent and adhere to supportive care and medication instructions, and to ensure that a patient understands when to seek medical attention (eg, treatment toxicity). ${ }^{6}$ The incidence of cognitive deficits increases with age. Studies in patients without cancer have shown an association between cognitive and physical function. ${ }^{7-9}$ In an observational study of 1787 community-dwelling patients aged 65 years and older, 50\% had some level of cognitive change. ${ }^{10}$ Feil et $\mathrm{al}^{11}$ reviewed the association between cognitive impairments and mortality risk in older adults with chronic illnesses, including cancer, and found that the effects were additive, such that subjects who were cognitively impaired at baseline had a $68 \%$ increased risk of mortality. ${ }^{11}$ Thus, testing for cognition in the oncology population may provide insight into decision-making based on life expectancy.

In 2010, the Patient Protection and Affordable Care Act (PPACA) recommended an annual wellness visit, including a cognitive assessment, for older adults enrolled in the Medicare program. ${ }^{12}$ However, the Centers for Medicare and Medicaid Services did not recommend a specific tool and noted that no nationally recognized tool exists for screening cognitive impairment. ${ }^{12}$ The United States Preventive Services Task Force (USPSTF) also found insufficient evidence to recommend for or against routine cognitive screening in older adult populations. ${ }^{13}$ The Alzheimer's Association convened a workgroup to develop recommendations on performing a cognitive assessment in primary care settings. ${ }^{14}$ The workgroup determined that a cognitive screen should be a stepwise process, that observation alone is not sufficient, that asking a patient about their memory changes can help determine who to test, and that a structured assessment should be performed at baseline and periodically for surveillance, and need for further evaluation would be based on screening outcome. ${ }^{14}$ The NCCN Clinical Practice Guidelines in Oncology (NCCN Guidelines) for Senior Adult Oncology ${ }^{5}$ suggest an approach to assessing cognitive function and evaluating decision-making in older adults with cancer (in this issue; to view subsequent updates to this guideline, visit NCCN.org). These NCCN Guidelines recommend evaluating a patient's cognitive function if 1) impaired cognition would affect the plan or delivery of care (ie, impact life expectancy or adherence to the treatment plan, or alter the risk/ benefit of the treatment); 2) the provider is concerned about a patient's decision-making capacity; 3 ) the team suspects that cognition is impaired; or 4) the patient or family/caregiver has concerns about a patient's cognitive function. ${ }^{5}$

\section{Validated Tools for Assessing Cognition}

Although several validated tools are used for assessing cognition, complex or time-consuming cognitive assessment instruments present barriers to their use and usefulness during visits with oncologists. The ideal tool would be simple and fast to administer, and have high sensitivity for identifying patients who require additional evaluation. The most commonly used tools that meet these criteria are the MiniMental State Examination (MMSE), the Montreal Cognitive Assessment (MoCA), and the Mini-Cog (Table 1). The MMSE, developed by Folstein et $\mathrm{al}^{15,16}$ in 1975 to detect cognitive impairment and dementia, has been widely used. However, although it detects dementia, it is not a good instrument for detecting mild cognitive impairment (MCI). Recently, other tools have been compared with the MMSE. The MoCA, developed as a screen for MCI, an intermediate state between normal cognition and dementia, and characterized by subjective memory impairment and preserved general function with intact ability to perform daily activities, is one such instrument. It has a higher sensitivity for detecting early cognitive changes than the MMSE. ${ }^{17}$ The Mini-Cog, a 3-minute validated instrument to screen for cognitive impairment, is simple and brief. ${ }^{18} \mathrm{~A}$ comparison of these 3 tools is outlined in Table 1. The previously mentioned Alzheimer's Association Workgroup reviewed 15 brief cognitive assessments for primary care settings and recommended the Mini-Cog, Memory Impairment Screen, or General Practitioner Assessment of Cognition (GPCOG). ${ }^{14}$ The Memory Impairment Screen is a verbal memory test that does not test visuospatial skills or executive 
McKoy et al

\begin{tabular}{|c|c|c|c|}
\hline Measure & MMSE & MoCA & Mini-Cog \\
\hline Time & $\begin{array}{l}5-10 \min \left(\text { Tombaugh and } \text { Mclntyre }^{16}\right) \\
\left.7 \text { min (Borson et } a^{18}{ }^{18}\right)\end{array}$ & $10 \mathrm{~min}$ & $3 \mathrm{~min}$ \\
\hline Detects & Severity of cognitive impairment & $\mathrm{MCl}$ and mild $\mathrm{AD}$ & Dementia \\
\hline Availability & $\begin{array}{l}\text { Required tool available at: http://www. } \\
\text { health.gov.bc.ca/pharmacare/adti/ } \\
\text { clinician/pdf/ADTI\%20SMMSE-GDS\%20 } \\
\text { Reference\%20Card.pdf }{ }^{9}\end{array}$ & $\begin{array}{l}\text { Required tool available at: } \\
\text { http://consultgerirn.org/ } \\
\text { uploads/File/trythis/try_- } \\
\text { this_3_2.pdf }{ }^{40}\end{array}$ & $\begin{array}{l}\text { No tool required; paper and } \\
\text { pencil only } \\
\text { Instructions can be downloaded } \\
\text { at: http://consultgerirn.org/ } \\
\text { uploads/File/trythis/try_this_3. } \\
\text { pdf } \text { f }^{41}\end{array}$ \\
\hline $\begin{array}{l}\text { Sensitivity/ } \\
\text { specificity }\end{array}$ & $\begin{array}{l}63 \%-100 \% / \\
52 \%-99 \%\end{array}$ & $\begin{array}{l}94 \%-100 \% / \\
35 \%-50 \%\end{array}$ & $\begin{array}{l}76 \%-99 \% / \\
83 \%-93 \%\end{array}$ \\
\hline Measures & $\begin{array}{l}\text { Orientation, immediate- and short- } \\
\text { term recall, working memory, } \\
\text { comprehension, and visuospatial }\end{array}$ & $\begin{array}{l}\text { Orientation, immediate- and } \\
\text { short-term recall, visuospatial, } \\
\text { phonemic fluency, attention, } \\
\text { abstraction, and executive } \\
\text { function }\end{array}$ & $\begin{array}{l}\text { Immediate- and short-term } \\
\text { recall, visuospatial, and } \\
\text { executive function }\end{array}$ \\
\hline Items & 30 points & 30 points & 3-word recall and clock drawing \\
\hline Scoring & $\begin{array}{l}\text { 24-30: normal } \\
\text { 18-23: mild impairment } \\
\text { 0-17: severe impairment }\end{array}$ & Normal $\geq 26$ points & $\begin{array}{l}\text { 0: positive for cognitive } \\
\text { impairment } \\
\text { 1-2: abnormal CDT then } \\
\text { positive for cognitive } \\
\text { impairment } \\
\text { 1-2: normal CDT then negative } \\
\text { for cognitive impairment } \\
\text { 3: negative screen for dementia } \\
\text { (no need to score CDT) }\end{array}$ \\
\hline Languages & 8 available & 36 available & $\begin{array}{l}\text { Any language in which the } \\
\text { tester is fluent }\end{array}$ \\
\hline Advantages & Level of impairment is measured & One-page tool & $\begin{array}{l}\text { Nonphysicians can perform } \\
\text { Not influenced by education or } \\
\text { language } \\
\text { Do not need a special tool }\end{array}$ \\
\hline Disadvantages & $\begin{array}{l}\text { Does not detect early disease } \\
\text { Highly verbal } \\
\text { Negatively impacted by demographic } \\
\text { factors (age, education) } \\
\text { Lack of sensitivity for } \mathrm{MCl} \\
\text { Does not measure visuospatial or } \\
\text { constructional praxis } \\
\text { Charges a fee for each use }\end{array}$ & $\begin{array}{l}\text { Tool is required } \\
\text { Education bias } \\
\text { Limited published data }\end{array}$ & $\begin{array}{l}\text { Scoring of clock relies on tester } \\
\text { judgment } \\
\text { Use of different word lists may } \\
\text { impact failure rates }\end{array}$ \\
\hline
\end{tabular}

Abbreviations: AD, Alzheimer disease; CDT, clock drawing test; $\mathrm{MCl}$, mild cognitive impairment; MMSE, Mini-Mental State Examination; MoCA, Montreal Cognitive Assessment.

function. ${ }^{19}$ The GPCOG was validated in primary care, but lacks data in other languages besides English ${ }^{20}$; low scores on any of these measures may indicate the need for further evaluation by a geriatrician, neurologist, geriatric psychiatrist, or neuropsychologist.

\section{Impact of Cognitive Function on Performance Status}

Decrements in cognitive function have been associated with impaired performance status; for example, the lower the MMSE score the less the functional independence. ${ }^{16}$ This association is important, because performance status helps to predict treatment benefit and tolerance among patients with cancer. Not surprisingly, cognition and physical function are intimately intertwined. Although someone with MCI will have preserved physical functioning, as cognition worsens and progresses to dementia, physical function deteriorates in tandem; this underscores the importance of measuring function along with cognition in older adults in general and those with cancer in particular.

The CGA measures function through assessing a patient's ability to perform activities of daily living (ADL), such as bathing, eating, dressing, transferring, and toileting. ADLs are tasks performed 
by each individual on a daily basis that are essential to independent living. ${ }^{21}$ The instrumental activities of daily living (IADL), which measure the ability to use the telephone, shop, prepare food, perform housekeeping chores or laundry, travel independently (using public transportation or driving), manage medications independently, and handle finances, are critical to living independently in the community. ${ }^{22}$ Undoubtedly, the more preserved the ADLs and IADLs are, the greater the chance of completing cancer therapy successfully. The Katz Index for ADLs and the Lawton Scale for IADLs can be quickly accessed online and easily scored; both are used extensively in the geriatric setting to evaluate functional status. ${ }^{21,22}$

In the 2014 updated guidelines, the NCCN Senior Adult Oncology Panel included a table highlighting the differences among $\mathrm{MCI}$, dementia, and delirium, including the distinguishing features, differential diagnosis, screening tools, and steps for further evaluation (Table 2). ${ }^{5}$ When MCI is suspected, the clinician can use the ADL/IADL and Mini-Cog screening tools and continue scheduled periodic assessment or reassessment when major changes occur in the patient's condition or treatment plan to identify progression to dementia. If warranted, the patient should be referred to a clinician experienced in cognitive evaluation. Dementia should be suspected if impairment of memory and at least one other involved cognitive domain occurs, such as aphasia (speech), apraxia (loss of ability to perform purposeful movement), agnosia (inability to recognize sensory inputs), or executive function (problem-solving, reasoning), and any decrements are seen in tasks of daily function. A dementia diagnosis requires a progressive loss of cognitive abilities that affects function. In some patients, more detailed neuropsychological testing performed by a trained clinician may be indicated. Because dementia may be from several reversible causes, vitamin $B_{12}$, red blood cell folate, and thyroid-stimulating hormone with reflex T4 levels should be evaluated as part of the cognitive workup. Brain imaging (noncontrast CT or MRI) is also part of a comprehensive cognitive workup, and the possibility of brain metastasis in the oncology population should be considered.

In contrast to $\mathrm{MCI}$ and dementia, delirium has an acute onset, may fluctuate in severity, and presents as a disturbance of consciousness (reduced ability to focus, sustain, or shift attention). Delirium is associated with negative long-term complications, including functional decline, increased length of hospital stay, restraint use, increased mortality, and development of dementia. ${ }^{23,24}$ Additionally, comorbid conditions can confound a cognitive diagnosis and must be considered when contemplating cancer treatment. Coexisting psychiatric diagnoses, such as depression, anxiety, or apathy, can initially appear as a cognitive impairment, and failure to identify and treat these mood disturbances early can derail cancer treatment in the long term. Other factors to assess and rule out as a cause for a presenting cognitive problem are drug or alcohol dependence, medication related side effects, insomnia, or other common geriatric conditions that can masquerade as confusion (eg, pain, infection, dehydration, constipation).

Oncology settings are busy, with little time for additional assessments; however, when an older patient or their caregiver presents with a complaint of altered memory, or the oncology treatment team suspects cognitive impairment, further evaluation should be performed. The Mini-Cog along with ADL/IADL assessment can be performed by nonphysician staff. If these tests are abnormal, further evaluation or referrals can be made. Patients with MCI should be monitored closely for progressive decline. Symptomatic patients may benefit from treatment with acetyl cholinesterase inhibitors, which may slow cognitive decline, thus allowing for more successful cancer treatment; however, a healthy lifestyle can be promoted, including good nutrition and engagement in physical activity. ${ }^{25}$

\section{Applying Legal Constructs to Capacity Determination}

Determination of patient capacity and/or competency is a critical cornerstone to obtaining informed consent for treatment or participation in clinical research and must be considered for every patient, including older patients contemplating cancer therapy. The notion of informed consent is based on the longstanding ethical construct that patients have an inalienable right to make decisions about their own bodies, and is similarly grounded in the penumbra of US Supreme Court case precedents on the right to privacy and bodily integrity. ${ }^{26}$ Capacity is defined as the clinical determination of fitness based on one's mental ability or function, whereas 
McKoy et al

\begin{tabular}{|c|c|c|c|}
\hline & Mild Cognitive Impairment & Dementia & Delirium \\
\hline Definition & $\begin{array}{l}\text { An intermediate state between } \\
\text { normal: cognition and } \\
\text { dementia characterized by: } \\
\text { - Selective memory impairment } \\
\text { - Preserved general cognition } \\
\text { - Intact ability to perform daily } \\
\text { function }\end{array}$ & $\begin{array}{l}\text { A progressive condition } \\
\text { characterized by: } \\
\text { - Impairment of memory and } \\
\text { at least one other cognitive } \\
\text { domain (aphasia, apraxia, } \\
\text { agnosia, executive function) } \\
\text { - Interference with ability to } \\
\text { perform daily functions }\end{array}$ & $\begin{array}{l}\text { Disturbance of consciousness } \\
\text { with: } \\
\text { - Reduced ability to focus, } \\
\text { sustain, or shift attention } \\
\text { - Onset over a short period } \\
\text { (usually hours to days) } \\
\text { - Fluctuation during the course } \\
\text { of the day }\end{array}$ \\
\hline Distinguishing features & $\begin{array}{l}\text { Subjective memory complains } \\
\text { and awareness of memory } \\
\text { changes } \\
\text { Preserved function }\end{array}$ & $\begin{array}{l}\text { Progressive (not sudden) loss of } \\
\text { multiple cognitive abilities } \\
\text { Affects the ability to function } \\
\text { independently }\end{array}$ & $\begin{array}{l}\text { Acute onset } \\
\text { Waxing and waning } \\
\text { Associated with physiologic } \\
\text { disturbances }\end{array}$ \\
\hline $\begin{array}{l}\text { Differential diagnosis } \\
\text { (confounding factors) }^{\text {a }}\end{array}$ & \multicolumn{3}{|c|}{$\begin{array}{c}\text { CNS metastases } \\
\text { Psychiatric disease (eg, depression, anxiety, apathy) } \\
\text { Endocrine dysfunction (eg, thyroid) } \\
\text { Metabolic causes (eg, vitamin } \mathrm{B}_{12} \text { deficiency) } \\
\text { Medication-related } \\
\text { Sleep disturbance } \\
\text { mmon geriatric conditions (eg, pain, infection, constipation) }\end{array}$} \\
\hline Screening tool & $\begin{array}{l}\text { Clinical interview with } \\
\text { functional assessment (ADLs/ } \\
\text { IADLs) and Mini-Cog }\end{array}$ & $\begin{array}{l}\text { Clinical interview with } \\
\text { functional assessment (ADLs/ } \\
\text { IADLs) and Mini-Cog }\end{array}$ & CAM \\
\hline Further evaluation & $\begin{array}{l}\text { Reassess periodically when } \\
\text { major changes in condition or } \\
\text { when considering treatment } \\
\text { plan } \\
\text { Consider consultation with } \\
\text { a clinician experienced in } \\
\text { cognitive evaluation }\end{array}$ & $\begin{array}{l}\text { Consult with a clinician } \\
\text { experienced in cognitive } \\
\text { evaluation and treatment } \\
\text { Neuropsychological testing may } \\
\text { be indicated } \\
\text { Evaluation: vitamin } \mathrm{B}_{12}, \mathrm{TSH} \\
\text { with } \mathrm{T4} \text {, brain imaging }\end{array}$ & $\begin{array}{l}\text { Evaluate and treat all potential } \\
\text { causes of delirium } \\
\text { Consider consultation with } \\
\text { clinicians experienced in } \\
\text { cognitive evaluation and } \\
\text { treatment }\end{array}$ \\
\hline
\end{tabular}

Abbreviations: ADLs, activities of daily living; CAM, Confusion Assessment Method; CNS, central nervous system; IADLs, instrumental activities of daily living; TSH, thyroid-stimulating hormone.

applies to all cognition categories.

competency refers to the legal determination that one is qualified or has the requisite or adequate abilities to function in a particular way. ${ }^{27}$

The American Medical Association's Code of Medical Ethics, Opinions E-8.08 ${ }^{28}$ and E-8, ${ }^{29}$ enumerate that physicians must provide relevant information to their patients, and that the full disclosure of relevant information to patients is intended to protect each patient's right to selfdetermination, bodily integrity, and voluntariness in the health care decision-making process. A patient's right of self-decision can be exercised effectively only if the patient has enough information to enable an informed choice; however, in special circumstances, it may be appropriate to postpone or withhold information. ${ }^{28}$ The notion of withholding information from a patient is labeled therapeutic privilege, because all information may not need to be communicated to the patient immediately or at one time; rather, the physician should assess the amount of information a patient is capable of receiving at any given time, and may tailor disclosure to meet patients' needs and expectations. ${ }^{29}$ Older patients in particular tend to defer decision-making to their physicians, and efforts must be made to actively include these patients in decision-making.

Reynolds $^{30}$ notes that the challenge of assessing decision-making capacity for treatment in the elderly is a matter of measurement reliability. If standardized criteria focus on IADL instruments, measuring and assessing decisional capacity can reliably use the performance assessment of self-care skills (PASS). ${ }^{31}$ Another measurement of decisional capacity using the MacArthur Competence Assessment Tool (MacCAT-T) is even more linked to meaningful assessment of cognitive function. ${ }^{32}$ Both of these tools, however, indicate a need for further evaluation and focused study to develop an integrated approach to assessing capacity that begins with the acknowledgment of adult multiple intelligences ${ }^{33,34}$ (and by extension the role of multimodal learning) and actual study of the differential relationships 
among neurologic, psychological, and cognitive abilities and decisional or functional capacity. To differentiate, other assessment tools focus, arguably, on traditional definitions of legal competency as a subcategory of capacity. The Capacity to Consent to Treatment Instrument (CCTI) uses hypothetical clinical situations and not only asks the patient to state a decision or answer questions about the situations but also asks for reasons why and gives credit for the total number of reasons given and the accuracy; in essence rating the choices. ${ }^{35}$ Moye et $\mathrm{al}^{35}$ compared the various assessment tools of CCTI, Hopkins Competency Assessment Test (HCAT), and MacCAT-T and noted that most adults with mild dementia can participate in medical decisions as defined by legal standards. Although memory impairment may limit understanding of diagnosis and treatment, assessment of reasoning regarding treatment options for patients with dementia could focus on whether the person can describe salient reasons for a specific choice. ${ }^{35}$ In comparison, Wilkins et $\mathrm{al}^{36}$ evaluated the role of HCAT as a standard part of the admission process to an inpatient geriatric psychiatry unit. The Wilkins study focused on evaluating capacity to make medical decisions and write an advance directive; if patients are able to comprehend and apply general information about medical decision issues, they are presumed to be able to make medical decisions on their own behalf. ${ }^{36}$ These various assessment tools become highly relevant for older patients with cancer because of the complex and specialized nature of the disease, its treatment, and its prognosis. Furthermore, if basic capacity can be demonstrated using any of the assessments, it is likely true that capacity to make decisions and be involved in one's medical treatment would also be demonstrated. Challenges arise when a decision must be made relative to an older individual with cancer who chooses, for example, to forgo treatment, or who chooses to pursue an orphan or expensive treatment with little or no likelihood of success in terms of progression-free and disease-free survivals.

In summary, competence is a legal construct determined by a court of law, but capacity to make medical decisions can be determined by any licensed physician on the treating team. Patients are deemed to retain decision-making capacity if they understand proffered treatment options, understand the reasons for the treatment options, are able to show reasoning behind their selected choices, and are able to communicate those choices. Although the choice may not align with that of the oncologist, a choice made along a reasoned continuum is considered to be an informed choice and treatment can proceed.

\section{Conclusions}

Remarkable strides have been made in the medical treatment of older individuals, but challenges remain as the number of older individuals increase in tandem with their comorbid illnesses. ${ }^{37}$ These challenges are most evident in oncology, where chemotherapy is inherently toxic and the potential for drug-drug interactions and adverse drug reactions increases. However, the availability of assessment tools can lighten the decision-making burden for both clinicians and older patients with cancer, and improve the clinician's ability to support the patient in making appropriate and accurate treatment decisions. For example, Schonberg et $\mathrm{al}^{38}$ developed and validated a prognostic index to predict 5-year mortality among community-dwelling older adults using 11 variables, including advanced age, comorbidities, ADLs, and lifestyle factors. Recruitment of instruments like this index to determine functional health status provides invaluable information to the treating oncologist faced with a chronologically older patient and uncertainty regarding the patient's physiologic reserve. Oncologists are encouraged to use the most time-friendly instruments in the armamentarium presented herein to screen their patients in concert with informed decision-making, and should refer to a geriatric practitioner when the instruments unearth potential cognitive or functional problems that require further expert attention.

\section{References}

1. Smith BD, Smith GL, Hurria A, et al. Future of cancer incidence in the United States: burdens upon an aging, changing nation. J Clin Oncol 2009;27:2758-2765.

2. United States Life Tables, 2008. National Vital Statistics Reports, Volume 61, Number 3. Available at: http://www.cdc.gov/nchs/ data/nvsr/nvsr61/nvsr61_03.pdf. Accessed August 9, 2013.

3. Stuck AE, Siu AL, Wieland GD, et al. Comprehensive geriatric assessment: a meta-analysis of controlled trials. Lancet 1993;342:1032-1036.

4. Elsawy B, Higgins KE. The geriatric assessment. Am Fam Physician 2011;83:48-56.

5. Hurria A, Wildes T, Blair SL, et al. NCCN Clinical Practice Guidelines in Oncology: Senior Adult Oncology. Version 2, 2014. Available at: NCCN.org. Accessed August 1, 2013. 
6. Girones R, Torregrosa D, Maestu I, et al. Comprehensive Geriatric Assessment (CGA) of elderly lung cancer patients: a single-center experience. J Geriatr Oncol 2012;3:98-103.

7. Dodge $\mathrm{HH}$, Kadowaki T, Hayakawa T. Cognitive impairment as a strong predictor of incident disability in specific ADL-IADL tasks among community-dwelling elders: the Azuchi Study. Gerontologist 2005;45:222-230.

8. Sauvaget C, Yamada M, Fujiwara S. Dementia as a predictor of functional disability: a four-year follow-up study. Gerontology 2002;48:226-233.

9. Wadley VG, Okonkwo $\mathrm{O}$, Crowe $\mathrm{M}$, et al. Mild cognitive impairment and everyday function: evidence of reduced speed in performing instrumental activities of daily living. Am J Geriatr Psychiatry 2008;16:416-424.

10. Landi F, Onder G, Cattel C, et al. Functional status and clinical correlates in cognitively impaired community-living older people. J Geriatr Psychiatry Neurol 2001;14:21-27.

11. Feil D, Marmon $T$, Unutzer J. Cognitive impairment, chronic medical illness, and risk of mortality in an elderly cohort. Am J Geriatr Psychiatry 2003;11:551-560.

12. Affordable Care Act. United States Department of Labor Web site. Available at: http://www.dol.gov/ebsa/healthreform. Accessed July 29, 2013.

13. Boustani M, Peterson B, Hanson L, et al. Screening for dementia in primary care: a summary of the evidence for the U.S. Preventive Services Task Force. Ann Intern Med 2003;138:927-937.

14. Cordell CB, Borson S, Boustani M, et al. Alzheimer's Association recommendations for operationalizing the detection of cognitive impairment during the Medicare Annual Wellness Visit in a primary care setting. Alzheimers Dement 2013;9:141-150.

15. Folstein MF, Folstein SE, McHugh PR. "Mini-mental state." A practical method for grading the cognitive state of patients for the clinician. J Psychiatr Res 1975;12:189-198.

16. Tombaugh TN, McIntyre NJ. The mini-mental state examination: a comprehensive review. J Am Geriatr Soc 1992;40:922-935.

17. Nasreddine ZS, Phillips NA, Bédirian V, et al. The Montreal Cognitive Assessment, MoCA: a brief screening tool for mild cognitive impairment. J Am Geriatr Soc 2005;53:695-699.

18. Borson S, Scanlan J, Brush M, et al. The mini-cog: a cognitive 'vital signs' measure for dementia screening in multi-lingual elderly. Int J Geriatr Psychiatry 2000;15:1021-1027.

19. Buschke H, Kuslansky G, Katz M, et al. Screening for dementia with the memory impairment screen. Neurology 1999;52:231238.

20. Brodaty H, Pond D, Kemp NM, et al. The GPCOG: a new screening test for dementia designed for general practice. J Am Geriatr Soc 2002;50:530-534.

21. Shelkey $M$, Wallace $M$. The Katz Index of Independence in Activities of Daily Living (ADL). Available at: http:// consultgerirn.org/uploads/File/trythis/try_this_2.pdf. Accessed August 7, 2013.

22. Graf C. The Lawton Instrumental Activities of Daily Living (IADL) Scale. Available at: http://consultgerirn.org/uploads/ File/trythis/try_this_23.pdf. Accessed August 7, 2013.

23. McCusker J, Cole MG, Dendukuri N, et al. Does delirium increase hospital stay? J Am Geriatr Soc 2003;51:1539-1546.
24. Andrew MK, Freter SH, Rockwood K. Incomplete functional recovery after delirium in elderly people: a prospective cohort study. BMC Geriatr 2005;17;5.

25. Ghetu MV, Bordelon PC, Langan RC. Diagnosis and treatment of mild cognitive impairment. Clin Geriatr 2010;18:30-36.

26. Tholen SL, Baird L. Con law is as con law does: a survey of Planned Parenthood v. Casey in the state and federal courts. Loyola Los Angel Law Rev 1995;28:971-1046.

27. Merriam-Webster Dictionary. Available at: www.m-w.com. Accessed June 26, 2013

28. American Medical Association. AMA's Code of Ethics. Opinion E-8.08: Informed Consent. Available at: http://www.ama-assn. org/ama/pub/physician-resources/medical-ethics/code-medicalethics/opinion808.page?. Accessed June 26, 2013

29. American Medical Association. AMA's Code of Ethics. Opinion E-8.082: Withholding Information from Patients. Available at: http://www.ama-assn.org/ama/pub/physician-resources/medicalethics/code-medical-ethics/opinion8082.page?. Accessed June 26, 2013.

30. Reynolds CF 3rd. Assessing the capacity to make everyday decisions about functional problems: where does the field go from here? Am J Geriatr Psychiatry 2007;15:89-91.

31. Rogers JC, Holm MB, Raina KD, et al. Disability in late-life major depression: patterns of self-reported task abilities, task habits, and observed task performance. Psychiatry Res 2010;178:475-479.

32. Grisso T, Appelbaum PS, Hill-Fotouhi C. The MacCAT-T: a clinical tool to assess patients' capacities to make treatment decisions. Psychiatr Serv 1997;48:1415-1419.

33. Gardner H. Multiple Intelligences: The Theory in Practice. New York, NY: Basic Books; 1993

34. Gardner, H. Frames of Mind: The Theory of Multiple Intelligences. New York, NY: Basic Books, 1983.

35. Moye J, Karel MJ, Azar AR, et al. Capacity to consent to treatment: empirical comparison of three instruments in older adults with and without dementia. Gerontologist 2004;44:166175.

36. Wilkins KM, Lund BC, McAdams JD, et al. Clinical utility of the Hopkins Competency Assessment Test on an in-patient geropsychiatry unit. Am J Alzheimers Dis Other Demen 2009;24:34-39

37. McKoy JM, Samaras AT, Bennett CL. Providing cancer care to a graying and diverse cancer population in the 21 st century: are we prepared? J Clin Oncol 2009;27:2745-2746.

38. Schonberg MA, Davis RB, McCarthy EP, et al. Index to predict 5 -year mortality of community-dwelling adults aged 65 and older using data from the National Health Interview Survey. J Gen Intern Med 2009;24:1115-1122.

39. Standardized Mini-Mental State Examination (SMMSE). Available at: http://www.health.gov.bc.ca/pharmacare/adti/ clinician/pdf/ADTI\%20SMMSE-GDS\%20Reference\%20Card. pdf. Accessed August 9, 2013.

40. Carolan Doerflinger DM. Mental Status Assessment in Older Adults: Montreal Cognitive Assessment: MoCA Version 7.1 (Original Version). Available at: http://consultgerirn.org/uploads/ File/trythis/try_this_3_2.pdf. Accessed August 9, 2013.

41. Carolan Doerflinger DM. Mental Status Assessment of Older Adults: The Mini-Cog ${ }^{\mathrm{TM}}$. Available at: http://consultgerirn.org/ uploads/File/trythis/try_this_3.pdf. Accessed August 9, 2013 